\title{
IMPLEMENTATION ASPECTS OF THE REMELTING MATERIAL IN THE PRODUCTION OF HIGH PRESSURE DIE CASTS ON THE ALUMINUM BASED ALLOYS
}

\author{
Ján MAJERNÍK, Martin PODAŘIL, Ladislav SOCHA, Karel GRYC \\ Institute of Technology and Business in České Budějovice, Faculty of Technology, Czech Republic, EU \\ majernik@mail.vstecb.cz, podari@mail.vstecb.cz, socha@mail.vstecb.cz,gryc@mail.vstecb.cz
}

https://doi.org/10.37904/metal.2019.961

\begin{abstract}
High pressure die casting technology is one of the most productive technologies for producing thin-walled aluminum parts in mass production. Along with high productivity, it offers high precision, very good surface quality, fine-grained texture without tightenings with good mechanical properties. One of the ways to increase the economic efficiency of the high pressure die casts production while adhering to the prescribed quality properties represented by the mechanical properties of casts, is using the remelted material in high pressure foundries. This contribution is conceived as a cross-sectional study of the remelted material implementation in the high pressure die casting technology. The study is focused on the technological and economic aspects of the remelted material implementation into the production of aluminum based high pressure die casts. The results of the operational experiments show that the proportion of the remelted material in the batch increases the porosity of casts, reduces the mechanical properties of casts and adversely affects the chemical composition of the input alloy. The proper ratio of pure and remelted material in the melt, while maintaining the prescribed quality requirements for cast, entails significant economic savings. The presented contribution serves as a summary of knowledge in the field of metallurgical preparation of aluminum alloys and implementation of remelted material into production.
\end{abstract}

Keywords: High pressure die casting, remelted material, mechanical properties, casts quality, aluminum alloys

\section{INTRODUCTION}

In terms of foundry industry, the most widely used materials are currently the aluminum alloys, because of their density, relatively good machinability and castability. The consumption of aluminum casts has increased by $65 \%$ over the last ten years, of which, up to $60 \%$ of all casts were made by high pressure die casting $[1,2]$. It is inevitable that the casting process was completely mastered because every saving and improving of casting parameters is reflected in overall economic balance in mass production. Frugality by using the input raw materials is beneficial for the economic balance of the company. The implementation of remelted material to the production contributes to the reduction of input material costs.

According to the practical experience, the proportion of remelted material depends on the size of the cast, from $75 \%$ for the large casts up to $20 \%$ of the cast weight for small casts. For cold chamber machines, it is up to $65 \%$ of the liquid metal weight, for the hot chamber machines it is up to $50 \%$. The remelted material must be degreased from the residues of greasy and separating means of petroleum origin. In the production of the less demanding casts in terms of quality, it is possible to use a lower quality alloy using the remelted material of second and third melting. The volume of second melting remelted material should not exceed $40 \%$ and the third melting remelted material volume should not exceed $30 \%$. In common technical practice, the pure remelted material (from the gating system, rejects) and contaminated (from filling chamber residues, alloy contaminated with oil) is fed into the melting furnace, melts, the new alloy is added in the blocks and then refined. It is better to use special furnace for the contamined remelted material and use this metal according to the achieved purity level for demanding or less demanding casts $[3,4]$. 
The aim of the contribution is to assess the impact of implementation of the remelted material on the production process in terms of mechanical properties of castings, chemical composition of the melt with the addition of the remelted material and economic savings caused by the implementation. In conclusion are expressed the assumptions and hypotheses on which will be driven the further research dealing with streamlining of the recycling and adding of the remelted material with regard on the maintaining the quality properties of casts.

\section{IMPACT OF THE REMELTING MATERIAL IMPLEMENTATION ON CHEMICAL COMPOSITION OF THE ALLOY}

Implementation of the remelted material into the melting process entails the risk of the primary element volume decreasing and increasing of the volume of the additive elements in the alloy. This drop is caused by a burnthrough of the remelted material. The team of authors [5] conducted the research of the remelted material impact on the chemical composition of the EN AC 47100 (AISi12Cu(Fe)). 7 experimental melting processes were compared with $0 \%, 10 \%, 20 \%, 30 \%, 50 \%, 70 \%$ and $100 \%$ of the remelted material volume in the batch. It arises from the experiments that during the melting process with $70 \%$ and $100 \%$ of the remelted material volume the measured chemical composition values does not meet the prescribed values for the given alloy specified in the EN 1706 [6], as shown in Table 1.

Table 1 The composition of alloy EN AC 47100 in wt\% according to the EN 1706 [6]

\begin{tabular}{|c|c|c|c|c|c|c|c|c|c|c|c|c|}
\hline Range & Al & $\mathrm{Si}$ & $\mathrm{Fe}$ & $\mathrm{Cu}$ & $\mathrm{Mn}$ & $\mathbf{M g}$ & $\mathrm{Cr}$ & $\mathrm{Ni}$ & $\mathrm{Zn}$ & $\mathrm{Pb}$ & Sn & $\mathrm{Ti}$ \\
\hline Min. & \multirow{2}{*}{ Residue } & 10.5 & $x x x$ & 0.7 & $x \times x$ & $x \times x$ & $x \times x$ & $x \times x$ & $x \times x$ & $x \times x$ & $x \times x$ & $x \times x$ \\
\hline Max. & & 13.5 & 1.5 & 1.2 & 0.55 & 0.35 & 0.1 & 0.3 & 0.55 & 0.2 & 0.1 & 0.2 \\
\hline
\end{tabular}

The publication [5] shows a change in the percentage proportion of individual elements in EN AC 47100 alloy depending on the proportion of remelted material added which is presented on the selected samples in Table 2.

Table 2 Chemical composition of the melt (wt\%) depending on the proportion of remelting material added [7]

\begin{tabular}{|c|c|c|c|c|c|c|c|c|c|c|c|c|}
\hline $\begin{array}{c}\text { Proportion of } \\
\text { remelting material }\end{array}$ & $\mathbf{A l}$ & $\mathbf{S i}$ & $\mathbf{F e}$ & $\mathbf{C u}$ & $\mathbf{M n}$ & $\mathbf{M g}$ & $\mathbf{C r}$ & $\mathbf{N i}$ & $\mathbf{Z n}$ & $\mathbf{P b}$ & $\mathbf{S n}$ & $\mathbf{T i}$ \\
\hline $0 \%$ & 85.72 & 11.56 & 0.75 & 0.89 & 0.29 & 0.32 & 0.02 & 0.02 & 0.35 & 0.02 & 0.03 & 0.03 \\
\hline $30 \%$ & 84.16 & 12.59 & 1.18 & 1.15 & 0.21 & 0.23 & 0.02 & 0.02 & 0.36 & 0.02 & 0.03 & 0.03 \\
\hline $100 \%$ & 82.50 & 13.38 & 1.63 & 1.65 & 0.17 & 0.19 & 0.02 & 0.02 & 0.36 & 0.02 & 0.03 & 0.03 \\
\hline
\end{tabular}

With the increasing percentage proportion of remelted material in the batch, a decrease in the proportion of $\mathrm{Al}, \mathrm{Mg}, \mathrm{Mn}$ in the batch was detected. Conversely, the elements $\mathrm{Fe}, \mathrm{Cu}$ and Si were increasing. The increased content of Fe can negatively affect the mechanical properties of casts.

If the content of iron does not exceed $1 \%$, it improves the castability of aluminum alloys, but is usually considered as an impurity. Its influence is manifested by its adverse effect on mechanical properties. In small weight percentage, it is considered to be a beneficial element as it increases the running property and strength of the alloy. However, the increase of the proportion causes a decrease in plastic properties and increases the brittleness of the material, the increase in porosity and tendency to the fissure formation. In Aluminum-Silicon alloys it causes a reduction in the silicon solubility in aluminum.

In the case of silicon, it increases the running property and the abrasion resistance and reduces the shrinkage coefficient during solidification and thermal expansion of alloys. 
Copper, when solidified, greatly extends the solidification interval of the Aluminum-Silicon alloys and thus can promote the formation of porosity and hot fissures. It increases the strength and hardness, reduces the ductility and impairs the corrosion resistance and significantly improves the machinability. The increase in Cu wt. \% has a beneficial effect on reduction of the material shrinkage during solidification and increases the ductility but reduces the corrosion resistance of casts.

Another element manganese increases the strength of aluminum at low quantity without reducing its weldability. It compensates the adverse effects of iron. In usual quantities, manganese does not affect the foundry properties. Due to the compensatory effect on the formation of unfavorable phases of iron, mechanical properties of alloys are increasing, the brittleness of alloys is decreasing.

In the case of magnesium, the hardening of aluminum alloys occurs [7].

\section{INFLUENCE OF REMELTING MATERIAL IMPLEMENTATION ON MECHANICAL PROPERTIES}

In the publication [5], authors dealt with the influence of the remelted material addition on the resulting mechanical properties of casts. The analysis of mechanical properties was focused on monitoring the values of permanent deformation, hardness and porosity of casts. Observing the values of permanent deformation, it has been shown that with increasing the proportion of remelted material in the batch the value of permanent deformation is increasing, and it is possible to assume a decrease of mechanical properties. Regarding to the measurements carried out, the authors stated an unequivocal negative impact of the remelted material on the casts quality. In accordance with GME 60007 [8], satisfactory results have been obtained only for casts made of melt with maximum $30 \%$ of remelted material in the batch (standard states permissible permanent cast deformation $s=0.025 \mathrm{~mm}$ ) [5]. Figure 1 depicts the dependence of permanent deformation on the remelted material proportion in the batch.

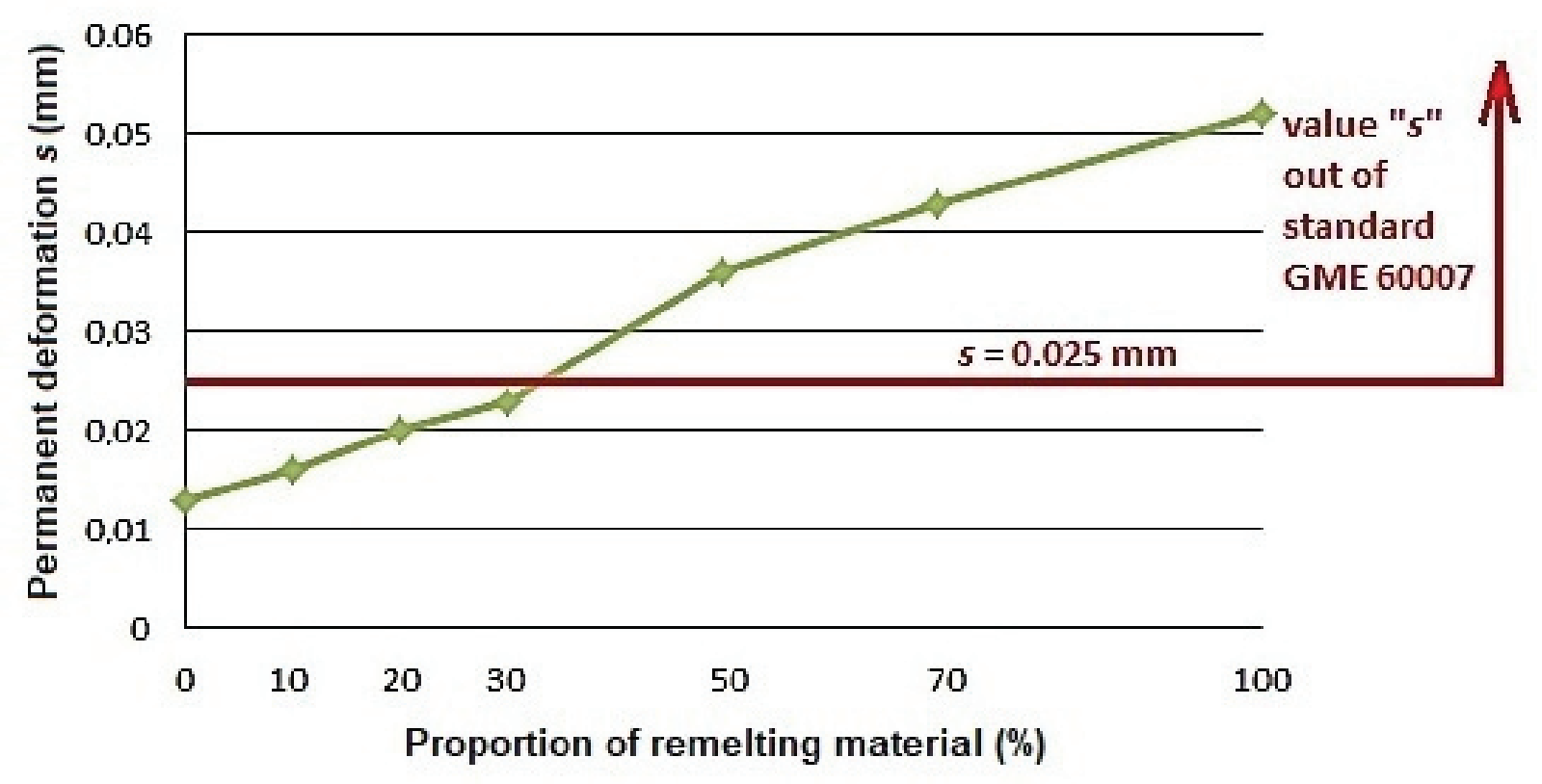

Figure 1 Dependence of the permanent deformation average values on the percentage proportion of remelted material

The assessment of porosity and macrostructures of casts made from individual melting processes also confirmed the influence of the remelted material proportion in the melt on the homogeneity of casts, which is depicted in Figure 2. With increasing remelted material proportion, an increase in porosity was observed with the formation of unacceptable size of pores [5]. 


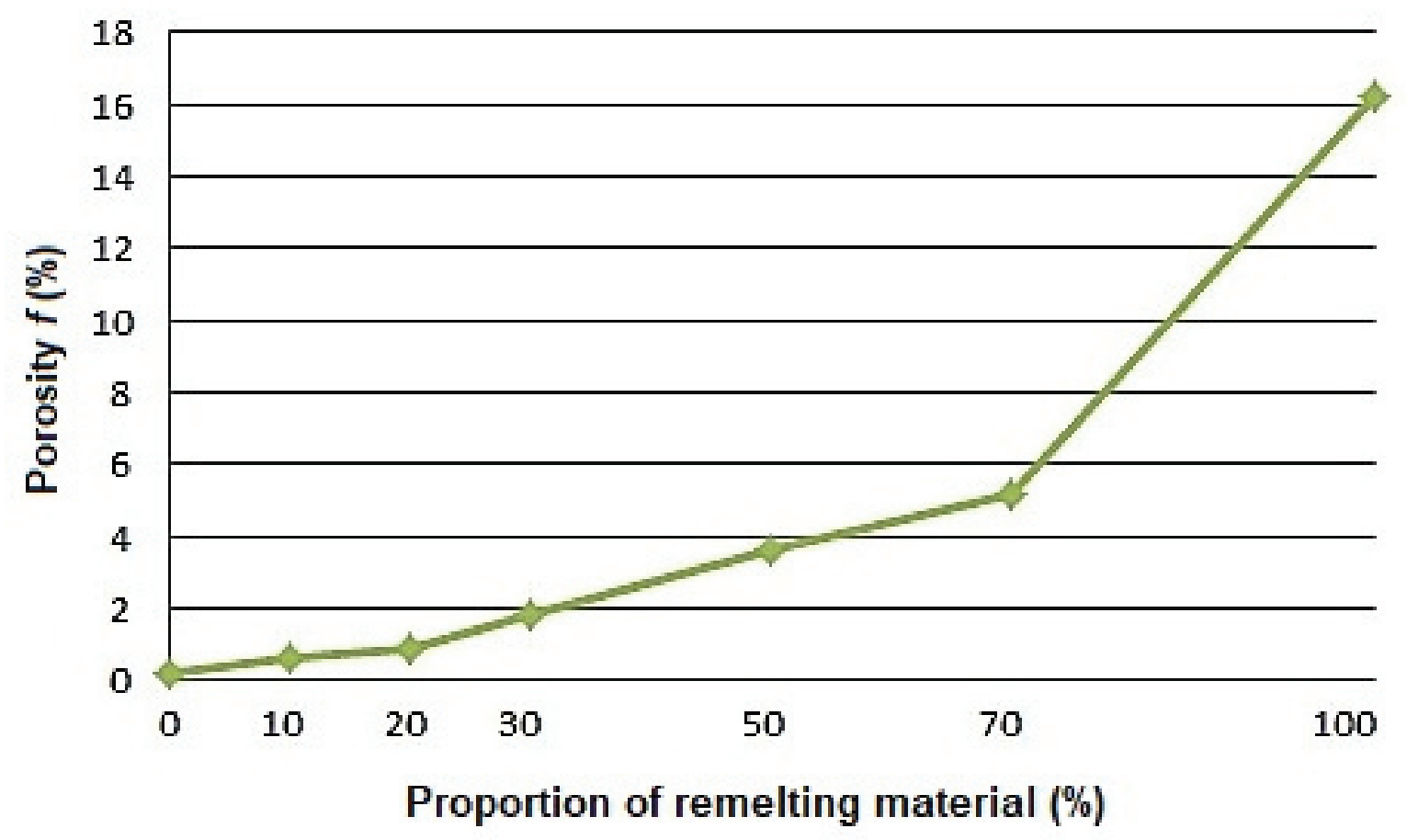

Figure 2 Dependence of porosity values on the remelted material percentage proportion

As both, the mechanical properties and the porosity values of the individual samples have deteriorated due to higher proportion of remelted material, it is justified to claim that the mechanical properties and the homogeneity of the casts are closely correlated. This statement is confirmed by a team of authors in the publication [9].

When assessing the surface hardness of individual casts manufactured of an alloy with an addition of increasing remelted material proportion, no remarkable effect was noted [5].

The mechanism for the crystallization of aluminum alloys as well as the formation of the structure and the impact on the casts surface hardness is explained in [10]. The determining factor affecting the value of the casts surface hardness is the degree of the undercooling in the melt-contact area with the mold face, and hence the velocity of the heat transfer from the melt to the mold volume.

\section{ECONOMIC ASPECTS OF REMELTING MATERIAL IMPLEMENTATION INTO PRODUCTION}

Based on the data presented in [5], an economic analysis of the costs associated with the waste production rate calculated on the production of 40 pieces of casts was conducted. With regard to monitoring the influence of remelted material implementation into production it is evident, that the addition of the remelted material in the batch is reducing the volume of waste in production. With respect to the mechanical properties of the casts, the values falling within the permissible interval determined by GM 060007 were evinced by casts manufactured by the melting process with $0 \%, 10 \%, 20 \%$ and $30 \%$ remelted material added (see Figure 1). The production was carried out using molds, each containing 4 casts. The weight of the aluminum alloy for the entire system was $3.26 \mathrm{~kg}$, the net weight of the 4 casts was $0.552 \mathrm{~kg}$. When melting from the $100 \%$ pure input material, the weight of the waste for production of 40 pieces of casts was determined to $27.08 \mathrm{~kg}$. After adding $30 \%$ of remelted material, the weight of the waste is reduced to $20.234 \mathrm{~kg}$, which reduced the waste by $25.27 \%$. Table 3 presents the calculations of the total weight of waste according to the proportion of the added remelted material. 
Table 3 Comparison of the waste accumulation during the production of 40 pieces of casts for utmost values of the remelted material proportion

\begin{tabular}{|c|c|c|c|c|}
\hline \multirow{2}{*}{$\begin{array}{l}\text { Number of } \\
\text { produced casts } \\
\text { (pcs) }\end{array}$} & \multicolumn{2}{|c|}{ Remelted material proportion (30 \%) } & \multicolumn{2}{|c|}{ Remelted material proportion (0 \%) } \\
\hline & $\begin{array}{l}\text { Consumption of } \\
\text { pure material }(\mathrm{kg})\end{array}$ & $\begin{array}{l}\text { Cumulation of } \\
\text { waste }(\mathrm{kg})\end{array}$ & $\begin{array}{l}\text { Consumption of } \\
\text { pure material }(\mathrm{kg})\end{array}$ & $\begin{array}{l}\text { Cumulation of } \\
\text { waste }(\mathrm{kg})\end{array}$ \\
\hline 4 & 3.26 & 2.71 & 3.26 & 2.71 \\
\hline 8 & 6.52 & 5.42 & 5.54 & 4.44 \\
\hline 12 & 9.78 & 8.12 & 7.82 & 6.19 \\
\hline 16 & 13.04 & 10.83 & 10.11 & 7.90 \\
\hline 20 & 16.3 & 13.54 & 12.39 & 9.63 \\
\hline 24 & 19.56 & 16.25 & 14.67 & 11.36 \\
\hline 28 & 22.82 & 18.96 & 16.95 & 13.09 \\
\hline 32 & 26.08 & 21.66 & 19.23 & 14.82 \\
\hline 36 & 29.34 & 24.37 & 21.52 & 17.53 \\
\hline 40 & 32.6 & 27.08 & 23.80 & 20.23 \\
\hline
\end{tabular}

In a specific numerical evaluation of the cost reduction of 40 pieces of casts production means a $6.85 \mathrm{~kg}$ decrease in input material consumption and a cost reduction of EUR 15.75 excl. VAT, considering EUR 2.30 excl. VAT/kg purchase price of the EN AC 47100 alloy. Savings and costs are reduced by EUR 2300 excl. VAT per 1 ton of material, considering the addition of $30 \%$ remelted material into the batch.

\section{CONCLUSION}

The contribution is devoted to the assessing the aspects of remelted material implementation into the production of high pressure aluminum die casts. As presented in the contribution, the addition of the remelted material to the batch positively affects the economic burden of the company, but it is essential to take into account the influence of the remelted material on mechanical and chemical properties of the alloy. The remelted material changes the chemical composition of the input alloy, reduces the mechanical properties and homogeneity of the casts. Therefore it is necessary to find an advantageous price/quality of casts ratio in foundries using the experimental testing.

The contribution is conceived as a part of the study of methods of remelted material implementation into production, on the basis of which further research will be carried out with the focus on the remelted material influence on casts quality properties. As presented, with the increasing proportion of remelted material in the batch, the proportion of $\mathrm{Fe}$ and $\mathrm{Cu}$ in the melt also increases. Partial research objectives are aimed at determining the influence of iron and copper on the mechanical properties of casts and corrosion resistance.

\section{REFERENCES}

[1] MALIK, Ján. Technológia tlakového liatia zliatin hliníka. $1^{\text {st }}$ ed. Košice: Technical university of Košice, 2013. p. 274.

[2] RAGAN, Emil. Liatie kovov pod tlakom. $1^{\text {st }}$ ed. Prešov: Fakulta výrobných technológií v Prešove, 2007. p. 381.

[3] PAŠKO, Ján and GAŠPÁR, Štefan. Technological Factors of Die Casting. $1^{\text {st }}$ ed. Lüdenscheid: RAM-Verlag, 2014. p. 93.

[4] RUŽBARSKÝ, Juraj, PAŠKO, Ján and GAŠPÁR, Štefan. Techniques of Die Casting. $1^{\text {st }}$ ed. Lüdenscheid: RAMVerlag, 2014. p. 199. 
[5] GAŠPÁR, Štefan, PAŠKO, Ján and HUSÁR, Josef. Technologické aspekty zavádzania vratného materiálu $v$ technológii tlakového liatia a ich vplyv na kvalitu odliatku. $1^{\text {st }}$ ed. Brno: Tribun EU s.r.o., 2018. p. 103. In Slovak.

[6] ČSN EN 1706. Aluminium and aluminium alloys - Castings - Chemical composition and mechanical properties. Praha: Czech Office for Standards, Metrology and Testing, 2010. p. 28.

[7] ROUČKA, Jaromír. Metalurgie neželezných slitin. 1 1st ed. Brno: Akademické nakladatelství CERM, s.r.o., 2004. p. 148. In Czech.

[8] GME 60007. Aluminiumteile für Treibwerklagerung und Aluminiumnenkerne von Dämpfungsblocken, Conti Tech Vegum VC.

[9] MAJERNÍK, Ján, KMEC, Ján and KARKOVÁ, Monika. Analysis of the impact of the construction of a gate on the macroscopic structure of a casting and its influence on the mechanical properties of castings. Manufacturing Technology. 2017. vol. 17, no. 1, p. 62-66.

[10] KARKOVÁ, Monika, MAJERNÍK, Ján and KMEC, Ján. Analysis of influencing the macrostructure and hardness of casting surface layer by changing conditions of crystallization. MM Science Journal. 2017. no. 12, pp. 1910-1913. 